\title{
ô Diez desafíos para América Latina en la década 2010 - 2020: ¿Hacia un neo regionalismo emergente?
}

Raúl Allard Neumann*

UNA REGIÓN DIVERSA QUE SIRVA DE PLATAFORMA PARA INICIATIVAS COMUNES.

América Latina, más que una denominación geográfica es una expresión político-internacional ya consolidada que identifica a un conglomerado diverso de países ex colonias españolas, portuguesas o francesas en el continente que son reconocibles como región con sentido de pertenencia a nivel de la comunidad internacional. Pese a sus diferencias, el concepto se complejiza y completa con la denominación más amplia de «América Latina y el Caribe», para incluir al Caribe insular de habla inglesa o ex colonias americanas inglesas y holandesas, en general. Por medio de diversos referentes aspira a tener una voz más concordante con su realidad territorial y demográfica en beneficio del desarrollo de sus pueblos, mientras otros sostienen que su influencia relativa más bien decrecería fruto del ascenso del Asia y otras áreas emergentes.

De modo creciente, los intercambios, escenarios, debates y oportunidades son globales y se presentan a nivel mundial y ese es el ámbito también en que deben tratarse grandes temas * Profesor y Director del Magíster en Relaciones Internacionales,
Pontificia Universidad Católica de Valparaíso. 
emergentes que exceden a las jurisdicciones nacionales. Está claro también que el refuerzo del multilateralismo, que refleje las actuales realidades en lo político, comercial y otros campos, va en beneficio de los países en desarrollo.

Esa mundialización no inhibe sino que hace necesaria, en el cambiante escenario de la primera parte del Siglo XXI, una articulación regional que permita y asegure un posicionamiento activo y eficaz, en beneficio de sus pueblos.

Es posible advertir que el avance de nuestra región en lo político, económico y social puede redundar en un peso relativo mayor, en la medida en que se aborden positivamente los desafíos que se presentarán entre el 2010 que ya expira y el año 2020. A continuación, y como aporte al debate público se indican-sintéticamente-algunos desafíos y tendencias que podrían configurar modalidades renovadas de cooperación regional:

\section{CONSOLIDACIÓN DE LA DEMOCRACIA}

La consolidación democrática ha sido una tendencia en la región en las dos últimas décadas y en lo sustantivo es un elemento fundamental para la vivencia del pluralismo y los derechos humanos y un desarrollo integrador. Aparte de Cuba, los gobiernos de la región han sido elegidos por las vías democráticas.

Diversos instrumentos internacionales han reforzado los procedimientos democráticos en cuanto a elecciones, derechos fundamentales a la asociación y la expresión y posibilidades reales de la oposición de ser gobierno si así lo deciden los pueblos por las vías constitucionales y legales. El tema de la democracia ha sido preocupación del sistema interamericano y la OEA, justamente, motivado porque aunque siempre la protección y el ejercicio de la democracia han estado presentes en las formulaciones teóricas y en el discurso, salvo excepciones, no lo ha sido así históricamente en los hechos.

Una expresión de esta tendencia es el Protocolo, acordado recientemente en la Cumbre de Guyana noviembre del 2010 en el marco de la UNASUR, que contiene criterios específicos y objetivos en materia de derechos políticos y democracia, así como promoción de sanciones políticas y diplomáticas en 
coordinación con otros esfuerzos internacionales de defensa de la democracia, cubriendo el acceso a funciones de poder y la continuidad democrática.

La mima línea se ratificó en diciembre del 2010 en Mar del Plata, Argentina, en la XX Cumbre Iberoamericana en la cual se adoptó la declaración «En defensa de la democracia y el orden constitucional en Iberoamérica» que establece un procedimiento en caso de amenaza de ruptura o alteración del orden democrático que afecte gravemente a un país, de lo que se dará cuenta a todos los miembros para la adopción de medidas concertadas. Si el orden constitucional se rompe se puede llegar por consenso a la suspensión del país.

Sin duda este tipo de definiciones se refuerzan mutuamente con otras como la Carta Democrática de la OEA -que después de una década está en proceso de profundización-y las cláusulas democráticas insertas en diversos tratados, lo que facilitará el diálogo al interior de la región y también con el Sistema Interamericano, la Unión Europea y el resto del mundo.

Según la encuesta de Latinobarómetro difundida en diciembre del 2010 y llevada a cabo en 18 países latinoamericanos, una proporción creciente de más del $60 \%$ de la población estima que la democracia es preferible a otro sistema (un porcentaje similar al de la aprobación que obtiene la empresa privada) y $44 \%$ se manifiesta conforme con el funcionamiento de la democracia en sus países. Sin duda un ambiente de opinión importante para procesos que deberán afianzarse en los próximos años y un desafío permanente de buen gobierno y transparencia para líderes, gobernantes, partidos y la «clase política», en general.

\section{CRECIMIENTO Y APERTURA ECONÓMICA: INSERCIÓN MUNDIAL Y NUEVOS ÉNFASIS Y MODALIDADES EN INTEGRACIÓN REGIONAL}

El denominado Consenso de Washington de comienzos de los años noventa ha quedado superado por su condición de políticas recomendadas o impuestas desde organismos como el FMI como condición de ayudas y préstamos y lo que se interpretó como un llamado al desarme del Estado de fun- 
ciones necesarias para orientar a los mercados y promover el desarrollo social, más allá de que ciertas tendencias relativas a apertura comercial, mayor peso del sector privado, IED y otras son parte de las políticas de la mayoría de los países. En todo caso, a los pocos años, el Banco Mundial, uno de los componentes del Consenso -según la expresión difundida por J. Williamson- abogó por la necesidad de un Estado moderno y eficaz, idea reforzada por los paquetes de estímulo fiscal a las economía con motivo de la crisis subprime y financiera del 2008, que tuvo origen en los países desarrollados.

El regionalismo abierto, propuesto por la CEPAL en diversos documentos entre 1990 y 1994 reflejó un llamado a conciliar las interdependencias tanto en la apertura de las economías al interior de la región latinoamericano, como en un comercio mas abierto con el resto del mundo. Ha sido importante en cuanto ha servido como base para políticas nacionales, incluso en países con énfasis y estrategias distintas en algunos aspectos, como Brasil y Chile. En general, admite más de una interpretación, desde su formulación original por Peter Drysdale, cientista político de la Universidad Nacional de Australia que al formularlo tuvo más en vista el tipo de apertura gradual y voluntaria del APEC y para quien lo abierto implicaba la adopción de los acuerdos multilaterales de la OMC en materia de liberalización del comercio de bienes(Acuerdo General de Aranceles Aduaneros y Comercio (GATTS, 1947 y 1994) y servicios General Agreement on Trade in Services (GATTS, 1994). Ha sido también criticado por algunos por significar una apertura considerable para algunas economías no preparadas para ello en los años noventa y también porque si bien aboga por la equidad y la coordinación productiva y de políticas, no sería un elemento central de la propuesta.

En la realidad actual, países como Brasil -identificado como potencia emergente y parte del BRIC junto a China, Rusia e India- y México han diversificado su producción y exportaciones y otros como Chile y Argentina han avanzado también en la internacionalización de sus empresas.

La realidad de la década que se inicia presenta una situación distinta de la de hace 20 años, en la mayor diversidad al interior de la región, en las nuevas oportunidades que ofrece el mundo emergente y en las que se pueden reabrir luego 
de que se superen las restricciones y secuelas post crisis de 2008 y 2009, particularmente en Estados Unidos y Europa. También los desafíos que presentan los temas emergentes que mencionaremos más adelante.

Se postula avanzar a nivel internacional hacia un sistema comercial más abierto, equilibrado, justo y transparente.

América Latina presenta a fines del 2010 un escenario complejo en que junto a su participación en los mecanismos multilaterales de regulación del comercio los distintos países forman parte de instancias subregionales de integración y suscriben una amplia gama de tratados y acuerdos comerciales bilaterales con países de dentro y fuera de la región latinoamericana. En el caso de Chile, el país ha ampliado su apertura unilateral de fines de los años setenta y ochenta con la apertura negociada durante los cuatro gobiernos de la Concertación de Partidos por la Democracia con los Presidentes Aylwin, Frei Ruiz Tagle, Lagos y la Presidenta Michelle Bachelet-actualmente a cargo del programa de la Mujer de las Naciones Unidas-, lo que está siendo continuado por el Gobierno del Presidente Piñera. En total, 28 tratados de libre comercio con 58 países y conglomerados-incluyendo Estados Unidos, la Unión Europea y China, se acaba de ratificar el TLC con Turquía, se suscribió uno con Malasia y se negocia con Viet Nam; simultáneamente es miembro de ALADI y miembro asociado de la CAN y el MERCOSUR y miembro de APEC y otras instancias.

Por su parte, una potencia emergente como Brasil ha diversificado su producción y exportaciones, es una potencia alimentaria mundial, tiene vastas reservas petrolíferas-que requerirán grandes inversiones por hallarse bajo el fondo del mar y desarrolla una política asertiva en los foros internacionales e incluso en continentes como África. Sus grandes empresas como Petrobras, Vale Rio Doce y otras operan a escala global. La encuesta de Latinobarómetro de diciembre 2010 le asigna una influencia en la región superior a la de Estados Unidos dando base a tesis como la del cientista político y diplomático Heraldo Muñoz sobre un «distanciamiento» relativo entre los Estados Unidos y América Latina, que en verdad sería más real en lo que respecta a América del Sur. La continuidad política 
del Presidente Lula y la futura Presidenta Dilma Rouseff es otro elemento positivo.

Argentina y Brasil son los miembros mayores del MERCOSUR junto con Uruguay y Paraguay, constituyendo una unión aduanera imperfecta que se ha visto afectada por diversas crisis y relanzamientos. Otros países como Perú y Colombia se han abierto también con éxito al comercio internacional, habiendo suscrito al igual que Chile TLC con Estados Unidos.

En este contexto se presenta una situación en que puede ser posible y conveniente ampliar y simplificar las preferencias arancelarias al interior del área latinoamericana y avanzar en la liberación del comercio intrarregional y en la armonización -hasta donde sea posible- de los distintos referentes, esquemas y acuerdos comerciales.

Los esfuerzos no deben ligarse necesariamente, por ejemplo, a planes nominalmente obligatorios y comprehensivos como las uniones aduaneras, que admiten variadas excepciones, no han logrado consolidarse en la región y en diversos casos han dejado de ser factibles en virtud de los acuerdos de libre comercio convenidos por algunos asociados con naciones extra regionales.

Con todo, en el momento actual, para una inserción externa ventajosa y para asegurarse el acceso a mercados importantes no son suficientes las normativas universales de la OMC. En este contexto, resultan necesarios tanto los acuerdos de integración regional -una base o plataforma regional- , como aquellos que faciliten el acceso a los mercados de otros países y regiones del mundo. Además, siempre está latente el proteccionismo de países desarrollados en agricultura y otros rubros. Esos temores que no se disipan con el Sistema General de Preferencias y sí se pueden superar por la vía de acuerdos comerciales formales.

Para materializar estas políticas, los países de la región cuentan con las experiencias en ALADI y los Acuerdos de Complementación Económica, MERCOSUR, SIECA en Centroamérica y en los tratados bilaterales de libre comercio, estudios del BID, CEPAL, SELA, ALBA y otros referentes, para coordinar posiciones en materias tales como reglas de origen, protección de la propiedad intelectual, subsidios, ventanillas únicas a nivel nacional, trato nacional, apertura de mercados agrícolas, 
exportación de servicios, inversión, cooperación aduanera y otras desde una perspectiva latinoamericana.

Estos criterios pueden servir, en lo intrarregional, para una mayor convergencia de esquemas existentes hacia un neorregionalismo basado más en las soluciones que en los conflictos, aun cuando estos vayan a resurgir periódicamente. Este regionalismo debe surgir con la impronta de la cooperación y la liberación del comercio y no la de poner obstáculos al comercio y los intercambios y requiere también de legislación complementaria como la relativa a asegurar la libre competencia. En todos estos puntos, se advierten las interacciones entre política y economía, Estado y mercado y sectores público y privado, que servirán de eje de los debates e interacciones de la década. Igualmente, estos servirán como base para posturas coordinadas - en la mayor medida posible- ante una reapertura de la Ronda de Doha a nivel de la OMC.

En suma, poseer como región la base necesaria para avanzar en la facilitación y liberación del comercio y los intercambios y el acceso a los mercados, a lo que se agregan inversiones mutuas y «joint ventures» y coordinación de políticas en temas de interés común, como se menciona más adelante.

Todo ello en una forma tal que queden a salvo las respectivas estrategias económicas internacionales y externas a la región de los distintos países.

Lo anterior debe complementarse en el curso de la década en la forma de un espacio latinoamericano crecientemente común en los intercambios culturales, cooperación científica y apoyos mutuos en educación, profundizando y completando los esfuerzos y exigencias de armonización y homologación de ciclos de estudios.

\section{Superación de Desigualdades y PROTECCión SOCIAL}

Las recomendaciones de la CEPAL en su $33^{\circ}$ período de sesiones de Brasilia, realizado en mayo-junio de 2010 apuntan a este tema insoslayable, «La Hora de la Igualdad. Brechas por cerrar, caminos por abrir». El crecimiento económico ha sido determinante, junto a políticas sociales, para disminuir 
la pobreza, pero no es suficiente para alcanzar mayores niveles de igualdad que se vinculan, entre otros factores, con las oportunidades educativas, la superación de la estratificación social y las reformas fiscales.

En los inicios del presente siglo se ha ido configurando una nueva agenda internacional de desarrollo que ha señalado la necesidad de abordar la lucha contra la pobreza desde una perspectiva multidimensional.

Esto implica el esfuerzo nacional y la cooperación intra y extrarregional que requiere el cumplimiento en la Región de las Metas de la Declaración del Milenio que suscribieron 189 países en Nueva York -y la erradicación de la pobreza extrema- y ya existen estudios de medio término en América Latina, coordinados por la CEPAL y con la participación de numerosos organismos, que dan a conocer los avances y la magnitud del desafío.

La primera meta del Milenio postula reducir a la mitad entre 1990 y 2015, el porcentaje de personas cuyos ingresos sean inferiores a un dólar diario, lograr empleo pleno y productivo y trabajo decente para todos, incluyendo mujeres y bajar entre 1990 y 205 el porcentaje de personas que padecen hambre. La segunda meta apunta al logro de la enseñanza básica universal y la tercera a promover la igualdad de género y el empoderamiento de la mujer.

Por su parte, el ya referido informe de la CEPAL pone énfasis en la capacidad -y voluntad- de formular de políticas adecuadas para abordar heterogeneidades estructurales, disparidades y brechas sociales. La igualdad de derechos como marco normativo a los pactos sociales.

\section{Política exterior en Un MUNDO CON \\ MULTIPLICIDAD DE ACTORES: DIÁLOGO CON \\ NUEVOS AGENTES TRANSNACIONALES Y DE LA SOCIEDAD CIVIL}

Esta materia incluye las reformas a nivel mundial y en la regulación del comercio -que se tratan más adelante-, y el reconocimiento de una naciente «nueva diplomacia» que incluye la interacción de las políticas exteriores de los Estado- 
naciones con organismos transnacionales, organizaciones no gubernamentales y con la naciente sociedad civil -y opinión pública- internacional.

En este sentido caven diálogos en foros consolidados como Davos, el Foro Económico Mundial y alternativos como Porto Alegre(el Foro Social Mundial) y encuentros y confrontación de posiciones con grupos que ya no son cerradamente antiglobalización- aunque sigan manifestándose con fuerza -sino que se autoidentifican como de globalización alternativa o contrahegemónica.

Los actores transnacionales asumen variedad de caracteres. Especial presencia son las de tipo ideológico cultural, como Amnesty International, OXFAM (que se internacionalizó en los años noventa luego de haberse originado en Oxford ,Inglaterra, durante la II Guerra Mundial para ayudar a combatir la hambruna en Grecia ocupada por la Alemania nazi) Greenpeace, Médicos Sin Fronteras, Caritas y las agrupaciones internacionales y redes de organizaciones no gubernamentales de diverso carácter que en muchos casos rescatan temáticas de interés público internacional. Distintos estudios calculan en 30 a 40 mil el numero de estos actores con diversas modalidades de acción, presión y financiamiento y muy activas en los medios de comunicación y la internet. En el ámbito económico están las empresas multinacionales o transnacionales -la UNCTAD reporta 79.000 casas matrices con 790.000 sucursales, que sirven de vehículo a la inversión extranjera directa, esto es, la que se lleva a cabo con propósitos de control. La gran mayoría de las empresas multinacionales tienen casa matriz en países industrializados, aunque es creciente la internacionalización de empresas de países en desarrollo.

En el ámbito político, actúan los movimientos de liberación.

En algunos casos, se han dado interacciones de organizaciones no gubernamentales con gobiernos a nivel mundial como los que condujeron a las convenciones que permitieron la proscripción de las minas antipersonales o el establecimiento de la Corte Penal Internacional, en que países como Canadá trabajaron sistemáticamente con estas organizaciones. También ha sido sintomático de la interacción de distintos tipos de actores la forma en que ha operado la difusión de la información «hackeada» y contenida en la web de WikiLeaks, 
creación de Julian Assange, sobre lo que volvemos al final. Assange llegó a acuerdo con varios medios (diario The Guardian de Londres el que a su vez incorporó al The New York Times de Nueva York, Le Monde de París, El País de Madrid y la revista alemana Der Spiegel) que, según se ha informado han revisado el material para descartar aquella información que pueda poner en peligro la seguridad de personas, proceso en el cual se formularían consultas al propio Gobierno de Estados Unidos. Una especie de anticipo de la complejidad de las relaciones internacionales en el siglo XXI.

La visión de un nuevo regionalismo en América Latina deberá considerar relaciones periódicas de diálogo constructivo con instituciones representativas de la sociedad civil internacional y actores transnacionales de distinto carácter, particularmente aquellos que sostienen objetivos de interés público.

Aunque los actores transnacionales no tienen aún en América Latina la fuerza que poseen, por ejemplo, en Europa, en la década que se inicia los Estados y los que diseñan e implementan políticas exteriores en la región deberán asumir de modo creciente esta multiplicidad de actores e intereses.

\section{AmÉrica latina EN LA POSTGUERRA Fría: CONVERGENCIA DE MECANISMOS DE INTEGRACIÓN Y ARTICULACIÓN DE POLÍTICAS Y PROPUESTAS, APORTES A LA NUEVA GOBERNANZA GLOBAL Y REFORMAS AL MULTILATERALISMO}

La visión de un nuevo regionalismo, que junto al perfeccionamiento y a la mayor justicia de las regulaciones de carácter universal y multilateral, pueda reconocer y asumir distintas realidades emergentes en los próximos años, requiere la articulación necesaria y flexible de los diversos mecanismos de integración política y económica y de facilitación del comercio en la forma expuesta en el párrafo 2.

En el caso de un mejor posicionamiento de América Latina para definir y coordinar sus demandas, la posición de México con una economía fuertemente orientada hacia el Norte y con una posición de bisagra en el NAFTA y América Latina -y como parte de ambos polos- no debe ser obstáculo para la 
cooperación a escala regional, pero puede hacerla más compleja. La emergencia del área sudamericana como ámbito de cooperación con la UNASUR puede fructificar y consolidarse en la década que se inicia y servir de punto de convergencia de la integración y cooperación caribeña, centroamericana, andina y del Cono Sur y otros referentes alternativos y en desarrollo, aunque la incorporación de otros Estados solo será posible después de cinco años. Se espera que en el transcurso de 2011 entre plenamente en vigor el Tratado de la UNASUR que agrupa a todos los países sudamericanos (Argentina, Bolivia, Brasil, al que le cupo un rol especial en la iniciativa con el liderazgo del presidente Lula da Silva, Colombia, Chile, Ecuador, Guyana, Paraguay, Perú, Suriname, Uruguay y Venezuela), tiene su secretaría en Quito y ha definido diversas áreas de cooperación y coordinación de políticas, tales como energía, integración física y turismo.

También hay ámbitos de cooperación de naturaleza mixta en que países latinoamericanos coexisten con otros de fuera de la región como en la OEA y el APEC.

Un caso especial es el Tratado de Libre Comercio P-4 o Transpacífico que tiene como miembros actuales y originales a Chile, Nueva Zelandía, Singapur y Brunei Darussalam y que tiene la particularidad de admitir nuevos miembros. En la práctica, la idea de transformar el APEC en un mecanismo más imperativo de libre comercio se ha canalizado por esta vía, particularmente por el interés demostrado por Estados Unidos -es el único tratado que dicha potencia negocia en la actualidad- y Australia, además de Perú y otros países y se está en la etapa de exploración y negociación. El Presidente de Chile, Sebastián Piñera destacó esta iniciativa en su participación en la reunión de líderes de APEC en noviembre 2010 en Japón. Va a ser interesante hacer seguimiento a esta iniciativa que, en el caso de Chile, tiene la complejidad de ya contar con un TLC con Estados Unidos. Otra realidad es la necesaria relación con potencias emergentes como China, Rusia, India y países como Turquía, la Unión Sudafricana y otros, y áreas de creciente cooperación y crecimiento como el sudeste del Asia. A lo que se suman, naturalmente, Brasil y los propias potencias emergentes de la región. 
La década que se inicia debe ser propicia para avances positivos en la situación de Cuba. En lo interno, en los cambios en lo económico impulsados por el Gobierno de Raúl Castro de modo pausado pero enfocados a ampliar el ámbito de la actividad económica privada y mayores interacciones en el plano económico internacional y los desafíos que deberá enfrentar en el mejoramiento sustancial de los derechos humanos y libertades políticas y en el respeto a la sociedad civil cubana que surge. En lo externo, y entre otros elementos, va a ser importante el acompañamiento del proceso por parte de las democracias latinoamericanas; por lo demás Cuba ya es parte activa del grupo de Río y de ALADI. Sin duda, estas relaciones se intersectan con las de Cuba con Estados Unidos, en que factores de política exterior y la Guerra Fría, primero y también de política interna en la actualidad retardan el levantamiento del bloqueo y solo han permitido medidas como el relajamiento de la normativa sobre viajes a la isla.

Así como España fue determinante en la última liberación de presos políticos y la propia Iglesia Católica de Cuba ha jugado un papel de acercamiento de posiciones, también pueden intentarlo los líderes latinoamericanos de modo más sistemático. Sin condonar excesos, pero igualmente sin desaprovechar oportunidades de encuentros a nivel político ni de relaciones entre pueblos y entre sus economías. Luego de medio siglo de desencuentros, es hora de la tendencia contraria.

A su vez, la nueva gobernanza a nivel global es un objetivo indispensable y requiere superar una institucionalidad internacional aún muy vinculada a las estructuras surgidas después de la II Guerra Mundial. Por lo demás, las transiciones en el poder mundial no van a ser fáciles pero sí diferentes esta vez a otras etapas históricas por la fuerte imbricación, por ejemplo, del ascenso del Asia y de China con los mercados occidentales y las tendencias globales del capitalismo internacional.

América Latina debe ser capaz de generar su propia agenda post Guerra Fría y junto con apoyar el multilateralismo y Nacional Unidas, propugnar su reforma y transformación de modo que refleje las realidades del mundo actual. Una articulación adecuada debe permitir también estar preparados para una eventual reanudación -pos crisis del 2008 y 2009- de la Ronda de Doha en el marco de la OMC y el perfeccionamiento 
de la regulación del comercio internacional, de modo que los acuerdos más bien genéricos que provienen de los acuerdos de Marrakech de 1994 puedan ser efectivamente negociados entre potencias desarrolladas y en desarrollo y no impuesto por aquellas. Existe también una creciente demanda de los países en desarrollo por una mayor participación en las decisiones a nivel del FMI y del Banco Mundial.

El mundo seguirá integrado por Estados-al tiempo que interactúan una gran gama de actores tradicionales y nuevos incluyendo por cierto la cooperación por medio de organismos internacionales gubernamentales necesarios para asumir tareas que superan al Estado-nación individual. Sin embargo, ello no debería ser óbice para ensayar aperturas innovadoras desde una perspectiva internacional, global o cosmopolita, como la nueva autoridad política mundial basada en el derecho propuesta en la Encíclica Caridad en la Verdad.

\section{AsUmiR LOS TEMAS EMERGENTES Y EL DESAFÍO AMBIENTAL ASÍ COMO LA COORDINACIÓN DE POLÍTICAS EN ÁREAS CLAVE}

Fenómenos como la interdependencia, la globalización y la relativa "permeabilidad» de las fronteras estatales y los cambios políticos que llevan consigo, han dado lugar a una nueva agenda temática que los gobiernos deben considerar. Envuelve temas tales como globalización y seguridad, medio ambiente, flujos migratorios, derechos humanos y democracia, al que ya nos referimos, crimen organizado e internacional y cooperación de las policías y en la lucha contra delitos específicos como el tráfico de drogas -el Convenio de Naciones Unidas contra el tráfico ilícito de drogas, que mencionamos más adelante por separado-, contrabando de armas, blanqueo de dinero y tráfico de personas, la expansión de las políticas públicas en el ámbito de la salud.

Asumir el desafío del cuidado y preservación del medio ambiente y garantizar su sostenibilidad es una condición ética del desarrollo y no puede quedar supeditada a exigencias externas. América Latina debe avanzar en la cooperación ambiental y para prevenir y abordar el calentamiento global, siendo parte 
activa en la determinación de los estándares en beneficio de las generaciones futuras. Uno de los mayores peligros de la globalización es que sea "depredadora", particularmente en América Latina. A partir de la Conferencia de Estocolmo de 1972 y pasando por la Conferencia de las Naciones Unidas en Río de Janeiro en 1992 y la Declaración de Río sobre Medio Ambiente y Desarrollo, se ha definido el concepto de "desarrollo sustentable», se vincula medio ambiente con condiciones económicas y problemas de justicia social y se sientan las bases de un nuevo orden jurídico internacional que incorpora lo ambiental y procura el balance con el componente económico social que el equilibrio del desarrollo sostenible reclama.

En el caso del calentamiento global, los esfuerzos en el marco de las Naciones Unidas, que resultaron insatisfactorios en diciembre del 2009 en la Cumbre de Copenhage están teniendo una nueva oportunidad en la conferencia de Cancún de noviembre-diciembre 2010, con miras a un acuerdo en materia de reducción de las emisiones de dióxido de carbono post 2012 y la búsqueda de compromisos por parte la comunidad internacional y países como Estados Unidos, China, India y otros, así como del efecto invernadero. En la conferencia de Cancún, algunos estudios técnicos proyectaron para el año 2050 una duplicación de precio de productos alimenticios como los cereales por el efecto del calentamiento global y la disminución de la productividad. Brasil, por su parte, por la vía del Presidente Lula presentó antecedentes que muestran en el último año(agosto 2009-julio 2010) una baja de la superficie de deforestación en el Amazonas -a un total de 6.450 kilómetros cuadrados en el año-, noticia recibida como positiva por su incidencia en el efecto invernadero. En general, el Acuerdo COP 16 tiene el aval de 194 países. La exigencia de cooperación se aplica a otros temas emergentes como el crimen organizado y el narcotráfico, sobre el que volvemos más adelante. Cabe mencionar que en la encuesta de Latinobarómetro de diciembre 2010 el tema de la criminalidad superó por segunda vez al desempleo como principal desafío.

En otro orden de cosas, diversos programas internacionales apuntan a la autonomía de las mujeres y a la igualdad de género, el derecho a la educación como eje del desarrollo humano el derecho a la salud y las respuestas de los sistemas 
de salud para alcanzar las metas en éste ámbito y el enfrentamiento de epidemias y pandemias y posiciones articuladas en temas como las migraciones, que son inevitables en un mundo mucho más interconectado y en que masas de trabajadores se desplazan hacia los que aparecen como polos de desarrollo más atractivos desde el punto de vista laboral. Este proceso ya se dio con mucha fuerza en la denominada «primera globalización» de fines del siglo XIX y comienzos del siglo XX.

Por su parte, la coordinación de las políticas nacionales debe estar en la base de un nuevo estilo de integración en la región, que debe fortalecer la solidaridad latinoamericana y facilitar otras políticas como la seguridad, como ya se adelantó para el caso específico de los objetivos de la UNASUR. Esto se aplica a programas coordinados en áreas como energía, transportes, integración física y vías de comunicación, turismo, salud, ventanilla única de comercio exterior que de hecho han partido en el marco de distintos referentes regionales y subregionales y son susceptibles de profundización y convergencia, generando bases y conocimiento mutuo para una integración mayor.

\section{COOPERACIÓN EDUCATIVA Y CULTURAL E INTERCAMBIO CIENTÍFICO Y EN NUEVAS TECNOLOGÍAS. El RETO DE LA COMPETIVIDAD, LA INNOVACIÓN Y EL EMPRENDIMIENTO}

La diversidad cultural es un valor, como también un plus el sentirse genéricamente latinoamericanos. Los intercambios en materia de creación artística y la mutua apreciación del patrimonio cultural -por medio del turismo cultural y otras vías- es un motor poderoso de construcción de la región.

Como se dijo al comienzo, como base para el desarrollo humano y la superación de la pobreza, es un desafío social y de competitividad. Sintomático del espíritu que prevalece en la región actualmente sobre el tema son las metas del Milenio al respecto y la declaración sobre «Educación para la inclusión social» adoptada por la Cumbre Iberoamericana del 2010 en Mar del Plata»-ya mencionada a propósito de la cláusula democrática- y que en las Metas de Educación para el 2021 establece la plena alfabetización para 2015 y un plan educa- 
tivo para la década que implicaría una inversión de cien mil millones de dólares para garantizar en la década «la cobertura universal y gratuita de la educación primaria y secundaria».

En lo científico tecnológico y en la «sociedad del conocimiento» como característica de la época se entrelazan ciencia y tecnología -duras y blandas-, innovación y emprendimiento. La creación de capacidad en ciencia e innovación es requerimiento de independencia. La superación del paradigma lineal que iba necesariamente desde el hallazgo científico a la aplicación concreta hace igualmente necesario apoyar sistemáticamente la investigación en ciencia, la investigación aplicada y tecnológica y la capacidad de innovar.

Sabemos que la tecnología es el principal factor de creación de valor en la sociedad moderna y, por ende, del desarrollo económico y social, en tanto la ciencia, además de lo que implica en el avance del conocimiento, ha sido también promotora del progreso tecnológico al proporcionar medios para desarrollo. La promoción de la investigación científica y tecnológica en la región, en la que corresponde un rol muy determinante a las universidades más complejas -y a la capacidad de investigación y formación de doctores tanto fuera como dentro de la región-, descansa en buena parte en políticas y fondos públicos a la que se asigna un rol en la creación, difusión y uso del conocimiento.

Igualmente, la identificación de «clusters» y sectores de nuevo desarrollo como lo están intentando diversos países que implica innovación e incorporación «cultural» de una técnica a la sociedad y el emprendimiento como la fase en que se generaría riqueza. Al igual que en otras latitudes, lo habrían hecho países que han logrado superar el subdesarrollo, como Singapur.

El desarrollo de las TIC, por su parte, como parte de los esfuerzos para disminuir la brecha digital, es señal a la vez de modernidad y de la ética de una nueva alfabetización. Todos los Estados son permeables a los flujos de las comunicaciones y los transportes y son, en consecuencia, más interdependientes que en el pasado.

Estos avances se vinculan también con un concepto ampliado de competitividad que incluye la necesaria mayor productividad pero que no se agota en ella. Los países compiten también en la calidad de su educación, la eficiencia y transparencia del 
Estado, la calidad de vida, la habilidad para innovar indicada más arriba, la estabilidad política y el manejo de su economía, así como en el «poder blando» de la cultura y la persuasión.

Lo anterior requiere finalmente de un rol activo de los Estados en el fomento de estas actividades. Igualmente, y en un sentido más amplio, se espera de los Estados una muestra de transparencia, modernización y eficiencia para coordinar los esfuerzos de las sociedades en pos del bien común.

\section{INCREMENTO DE LA INVERSIÓN EXTRANJERA}

DIRECTA (IED) LATINOAMERICANA.

La IED ha sido una de las características del proceso de globalización y aunque en los últimos siglos han existido empresas europeas que operaban en ultramar, el fenómeno se masificó a partir de 1970, principalmente con firmas con casa matriz en Estados Unidos, Europa Occidental y Japón. Las empresas multinacionales o transnacionales son las vías por las que se materializa la IED, considerada como aquella con propósitos de injerencia o control de la gestión y en que, por lo general las sucursales se instalan y registran en el país receptor de la inversión. En los países en desarrollo normalmente refuerzan el sector moderno y exportador y son parte del proceso de «deslocalización», particularmente de la industria manufacturera.

Es importante quiénes y dónde se adoptan las decisiones y junto con una apertura al comercio y con la inversión globales, según los intereses de cada país, dentro de las regulaciones del comercio internacional hay diversas formas de incentivar a las empresas asentadas en un país determinado en su expansión internacional.

En las dos últimas décadas y según lo muestran los informes anuales de la UNCTAD ha aumentado la provisión de IED por parte de empresas con base en el mundo en desarrollo, y también en el caso de América Latina siendo las empresas «translatinas» los mayores aportantes o proveedores de inversión en la región -y fuera de ella-, Brasil, México, Chile y Argentina.

Así, los países latinoamericanos son tanto proveedores como receptores de inversión extranjera directa. Por lo demás, 
y a diferencia de la década de 1960 que el tema era discutido con ribetes ideológicos, actualmente los países compiten en la atracción de inversiones, incluyendo las diplomacias presidenciales como la que practica el Presidente de Perú, Alan García.

Esta expansión facilita a nivel regional la diversificación de producciones destinadas tanto al nivel local como externo y su condición de "puente» para otras áreas, a la vez que significa un aprendizaje en terreno conocido para inversiones en mercados más lejanos.

En el presente decenio se verán intentos de orientar la inversión hacia sectores productivos -según la realidad de cada país-, así como de apoyar la internacionalización de las PYME en el comercio y la inversión, lo que está ligado también al crecimiento del sector servicios. La línea que facilita a las PYME elaborar productos intermedios para grandes productores o incursionar en nuevas tecnologías y proyectos innovadores se verá facilitada por el concepto ampliado de competitividad a que hemos hecho referencia. A nivel internacional también es recurrente el crecimiento de las adquisiciones y «mergers» o fusiones transfronterizas de empresas, lo que también están practicando las «translatinas» en su fase de internacionalización.

En décadas pasadas no tuvieron éxito los esfuerzos por lograr un acuerdo internacional de inversiones (AMI) de carácter imperativo y la materia es producto de numerosos acuerdos bilaterales o de orientaciones de organismos como la OCDE -en materias de estándares laborales, protección de inversiones y otras- o de carácter voluntario como el Pacto Global gestionado por el Foro Económico Mundial y que ha contado con apoyo de las Naciones Unidas. Esta es otra área en que los líderes latinoamericanos, con la necesaria interacción público-privada, van a estar llamados a consensuar criterios en el decenio que se inicia.

\section{LUCHA CONTRA LA CORRUPCIÓN Y EL NARCOTRÁFICO}

La transparencia es señal de verdadera modernidad y desde hace varias décadas el crimen organizado a nivel internacional ha requerido crecientemente coordinación y cooperación 
internacionales. El Convenio de las Naciones Unidas contra el tráfico ilícito de drogas y otras sustancias psicotrópicas de 1988, está en vigencia desde 1990.

El narcotráfico- y la acción de los carteles- afecta y destruye personas, desestabiliza instituciones y entroniza situaciones de violencia que afectan a todos y particularmente a zonas urbanas de desarrollo precario.

$\mathrm{Su}$ combate, como en diversos desafíos globales, no es posible sin que la sostenga una fuerte capacidad de decisión política, cohesión social y articulación público-privada en lo interno y la cooperación externa. Todo ello con la necesaria correlación de prevención, ataque a las causas y control de los efectos dañinos.

A fines del 2010 preocupan especialmente situaciones como la de las FARC en Colombia, de larga duración, en que al conflicto armado se une el narcotráfico considerado como elemento que prolonga el conflicto. Colombia ha contado con el apoyo de Estados Unidos en la lucha contra el narcotráfico por la vía del Plan Colombia. Más recientemente, la situación en México ha implicado situaciones de violencia particularmente en el norte del país. Por su parte, Brasil con ayuda de la policía militar ha realizado acciones decididas para liberar de la droga a «favelas» de Río de Janeiro, que será Sede del Campeonato Mundial de Fútbol el 2014 y de los Juegos Olímpicos en 2016.

Este es un tema presente en programas de la OEA en las últimas tres décadas y que crecientemente se incluirá en la cooperación propiamente latinoamericana.

\section{IO. SOLUCIONES POLÍticAS A CONFLICTOS ARMADOS Y ARREGLO PACÍFICO DE CONTROVERSIAS}

En el curso de la primera mitad del siglo XXI -y más temprano que tarde- debería llegarse a internalizar la noción y la realidad de que «la guerra sea imposible», como se ha instalado, por ejemplo, en el área de la Unión Europea. Este objetivo político y de seguridad fue considerado por sus precursores en la génesis misma de ese proceso integrador, en los años siguientes a la II Guerra Mundial. 
Mecanismos de encuentro, colaboración y superación de recelos intrarregionales-además de los instrumentos jurídicos de resolución de conflictos-son elementos básicos para la creación del clima adecuado. La capacidad de diálogo intra y extrarregional, la voluntad política y mucho valor y racionalidad en los liderazgos son condiciones para su aplicación. Esto implica políticas de defensa en que seguridad y desarrollo se vinculan a estabilidad internacional y cooperación.

\section{TENDENCIAS Y ESCENARIOS PARA UNA REGIÓN MÁS ASERTIVA. UN NEORREGIONALISMO MADURO Y NO EXCLUYENTE}

Estos lineamientos y escenarios posibles no son un ejercicio de futurología sino que pueden identificarse a partir y como proyección de realidades actuales y envuelven el desafío de desarrollar un regionalismo nuevo y adaptado a realidades emergentes, en un mundo en que interactúan actores nacionales e internacionales de muy diversa naturaleza.

La segunda década del siglo XXI se inicia con un sistema internacional sin orientaciones definidas.

Junto a grandes potencias como Estados Unido, que aún lucha por superar la crisis y sigue siendo la primera potencia mundial y la gran potencia nuclear, China, de creciente poderío en los ámbitos político, económico y militar, y economías poderosas como Alemania, Japón o la propia Unión Europea que también ha sufrido situaciones críticas, así como potencias emergentes de creciente significación, actúan y tienen alta presencia organismos internacionales con cierta tradición y que requieren de reformas profundas. Aparecen nuevos referentes para abordar situaciones y crisis contingentes como G-6, G-7, G-8 y G-20 que integran Argentina, Brasil y México, entre otros. Junto a este mundo internacional actúan los actores políticos internacionales no gubernamentales a los que ya nos referimos, muchos de los cuales conforman la nueva realidad de la sociedad civil internacional, actúan de observadores o como grupos de presión frente a organismos y conferencias internacionales mencionados en la propia Carta de las $\mathrm{Na}$ - 
ciones Unidas en el título relativo al Consejo Económico y Social y conforman la trama actual del sistema internacional.

Esta heterogeneidad debe ser vista como un campo de oportunidades para los países de América Latina que a pesar de sus diversidades tienen posibilidades reales de convergencia.

En este amplio marco de cooperación se asumen nuevas situaciones, actores, retos y procesos propios del siglo XXI. América Latina, con su variedad y a la vez con su potencial de consensos y solidaridad en distintos planos, se presenta ante la comunidad internacional con liderazgos renovados, una mayor asertividad, reconociendo sus propias diferencias y déficits y con la ventaja relativa de haber soportado la crisis financiera de 2008 y 2009 en mejores condiciones que otras áreas. La región aparece en general en buen pie económico. Sin embargo, Estados Unidos y Europa -que se ha visto afectada por las situaciones y rescates de Grecia e Irlanda-constituyen el $40 \%$ de la economía mundial y si su recuperación se retarda sin duda afectará la capacidad exportadora de nuestras economías.

Diferencias como las que puedan producir con la República Bolivariana de Venezuela y el ALBA -a los que indudablemente se aplican los distintos objetivos y requerimientos aquí expresados-, pueden ser tratadas con más perspectivas de solución si se dan en un terreno en que paralelamente y de modo cuotidiano se generan acercamientos y actividades comunes. Venezuela ha definido una orientación hacia «el socialismo del siglo XXI» con un discurso antiimperialista, lleva adelante una política exterior activa y de presencia universal en países como Irán y la Federación de Rusia y promueve el ALBA como referente, a la vez que participa en los distintos referentes latinoamericanos y sudamericanos y mantiene una política relativamente amplia en lo relativo a inversiones para prospecciones y explotación petrolera. En lo interno, a partir de 2011 el Poder Legislativo contará con una oposición minoritaria pero fuerte.

Además, en los últimos años, los países de la región han advertido la conveniencia de aunar posiciones frente a las reformas a la gobernanza global y a las Naciones Unidas y al sistema de seguridad, así como a la institucionalidad económica proveniente de Bretton Woods con el FMI, el Banco Mundial, y el GATT, que a partir de 1994 se ha integrado a 
la OMC, o a Cumbres Interamericanas con Estados Unidos y Canadá -la última de las cuales se realizó en Trinidad y Tobago- e Iberoamericanas con España y Portugal -que se llevará a cabo en el presente mes de diciembre de 2010 en Mar del Plata-, y a conferencias y referentes a nivel mundial o reuniones birregionales con Europa o de los líderes del APEC-para algunos países de la región. Igualmente, a nivel regional se advierten tendencias y coincidencias en los procesos democratizadores, de presencia de la sociedad civil y avances en lo económico y en las relaciones económicas internacionales, con sus correspondientes altibajos. Si bien se trata de tendencias regionales, cabe mencionar solo a vía de ejemplo, un grupo creciente y variado de países latinoamericanos como Argentina, Brasil, Chile, Colombia, Costa Rica, México, Panamá, Perú, República Dominicana, Uruguay y otros, así como Barbados, Trinidad Tobago y otros en la zona del Caribe anglófono, que junto con otros han profundizado este proceso gradual de convergencia, más allá de las fortalezas y fragilidades institucionales existentes.

Es sintomático también que ante serios conflictos internos en Bolivia y Ecuador, junto con la de otros organismos, se haya producido una intervención política inmediata y a nivel presidencial de la UNASUR.

No todos forman parte de la totalidad de los referentes y las conferencias latinoamericanas ampliadas como la de Costa de Sahuipe siguen siendo una excepción, pero a partir de ellos y otros pueden alcanzarse consensos en crecientes instancias y aspectos políticos, económicos, sociales y culturales que incluyan a todos. Será la propia satisfacción de necesidades comunes para los pueblos la fuente impulsora de los acercamientos. Lo regional no aparecerá como impuesto sino como una contribución de soluciones regionales a problemas nacionales y locales.

Un tema no fácil de calibrar en la actualidad, comienzos de diciembre de 2010 es el efecto que pueden tener las filtraciones de WikiLeaks ya mencionados -250.000 cables de la diplomacia norteamericana a nivel mundial que se están difundiendo por la vía de cinco medios periodísticos que tuvieron acceso a la información- en las relaciones internacionales en general y en las de América Latina y Estados Unidos en 
particular. Aunque es prematuro decirlo, si bien van a causar incomodidades y recelos y requerirán explicaciones, no deberían significar grandes cambios, aunque sí darán lugar a una mayor discreción y menos apertura a futuro en las opiniones que se vierten en contactos privados que siempre han sido- $y$ seguirán siendo- parte de los canales diplomáticos, en que la plena transparencia simplemente no sería posible. De algún modo, se ha adelantado la apertura de fuentes que tardan años o décadas en develarse. La actuación de WikiLeaks es una demostración práctica de la variedad de actores no estatales que están afectando el sistema internacional.

También resultan necesarias las actividades convergentes con otras instancias como las Naciones Unidas ante catástrofes naturales o situaciones de amenaza a la paz y la seguridad como la contribución de América Latina a la MINUSTAH en Haití. Con toda su complejidad, esta operación ha sentado las bases para la experiencia de servicio civil y militar de la región puede ser decisiva en la solución de sus propios problemas. Igualmente hay temas propicios para el trabajo común a nivel interamericano y de la OEA como los derechos humanos y la preservación de la democracia.

En suma, se trata de conciliar el sentido de pertenencia a una región y la conciencia de determinados intereses y desafíos comunes, por una parte, con la flexibilidad que requieren ésta y las distintas regiones -y sus Estados- para encontrar soluciones justas a nivel internacional y en escenarios multilaterales y poder interactuar así eficazmente en lo político, económico, social y cultural en beneficio de sus pueblos en una sociedad crecientemente global.

Un neo regionalismo maduro y no excluyente que permita a América Latina actuar internacionalmente de modo efectivo sería la correspondencia actual a los sueños ya bicentenarios de mayor solidaridad e integración de América Latina. Un «empoderamiento» de la región sin la connotación tradicional del juego suma cero de enfrentarse a otro, sino para aportar constructivamente al debate mundial en la búsqueda de una mayor justicia internacional y la creación de capacidades para abordar en conjunto los problemas emergentes. 